\title{
Pengaruh Pendapatan Asli Daerah dan Dana Perimbangan terhadap Belanja Modal di Kabupaten/Kota Provinsi Sumatera Utara
}

\author{
Eve Ida Malau \\ Sekolah Tinggi Akuntansi dan Manajemen \\ Indonesia \\ eveidamalau@gmail.com
Victor Marudut Mulia Siregar
Politeknik Bisnis Indonesia
victor.siregar2@gmail.com

\author{
Calen \\ Sekolah Tinggi Akuntansi dan Manajemen \\ Indonesia \\ calen.chan88@gmail.com
}

Kharisma Yudha Saragih
Politeknik Bisnis Indonesia
new.yudha10@gmail.com

\begin{abstract}
The objective of the research was to analyze the influence of original local revenue and balance funds partially on the capital expenditure in districts / towns of North Sumatra Province. The amount of capital expenditure for each region varies according to the size of the region and the needs of the region. The realization of capital expenditure in each region can show the economic progress of a region. Based on data that the author obtained from the website of the Director General of Fiscal Balance, there is still a capital expenditure budget that has not been maximally realized for regional development The population was 33 districts / towns of North Sumatra Province years of 2010-2018 and population will be used as sample. The data were processed by using panel data regression statistical method. The result of the research that original local revenue and balance fund had positive and significant influence on the capital expenditure in districts / towns of North Sumatra Province.
\end{abstract}

Keywords : Original Local Revenue, Balance Fund, Capital Expenditure.

\section{PENDAHULUAN}

Keberhasilan pengelolaan keuangan daerah melalui pengeluaran belanja modal dapat dilihat dari ketersediaan infrastruktur yang sesuai dengan kebutuhan masyarakat. Belanja modal merupakan pengeluaran yang digunakan untuk menambah aset tetap yang manfaatnya melebihi satu tahun anggaran. Belanja modal akan menambah belanja rutin seperti biaya pemeliharaan dan biaya administrasi umum (nufus \& Asmara, 2017) (Yawa \& Runtu, 2015). Besarnya belanja modal setiap daerah berbedabeda sesuai dengan luasnya daerah dan kebutuhan daerah. Realisasi belanja modal pada masing-masing daerah dapat menunjukkan kemajuan ekonomi suatu daerah. Berdasarkan data yang penulis peroleh dari situs Dirjen Perimbangan Keuangan, masih terdapat anggaran belanja modal yang kurang direalisasikan secara maksimal untuk pembangunan daerah, hal ini dapat dilihat dari masih banyaknya kerusakan jalan, drainase, dan fasilitas yang menunjang aktivitas publik di berbagai daerah.

Alokasi belanja modal dapat diperoleh dari berbagai sumber seperti Pendapatan Asli Daerah 
(PAD) dan Dana Perimbangan (Wandira, 2013). Pendapatan asli daerah adalah pendapatan yang diperoleh daerah berdasarkan peraturan daerah untuk membiayai belanja daerah (Nurdiwaty, Zaman, \& Kristinawati, 2017) (Juniawan \& Suryantini, 2018). Pendapatan asli daerah bersumber dari pemanfaatan sumber daya yang dimiliki oleh daerah. Penelitian menunjukkan bahwa pendapatan asli daerah berpengaruh positif dan signifikan terhadap belanja modal, artinya kenaikan pendapatan asli daerah maka akan searah dengan kenaikan belanja modal (Priambudi, 2017) (Pratiwi, 2019) (Pelealu, 2013) (Tuasikal, 2008). Sedangkan penelitian yang dilakukan di kabupaten/kota provinsi Jawa Tengah menunjukkan bahwa pendapatan asli daerah tidak berpengaruh terhadap belanja daerah, yang artinya kenaikan pendapatan asli daerah tidak mempengaruhi kenaikan belanja modal (Adyatma \& Oktaviani, 2015).

Dana perimbangan merupakan dana yang diperoleh daerah dari pemerintah pusat yang digunakan untuk pemerataan pembangunan daerah (Suryana, 2018) (Asmawati, Saragih, Panjaitan, \& Kumala, 2019). Dana perimbangan terdiri dari Dana Alokasi Umum (DAU), Dana Alokasi Khusus (DAK), dan Dana Bagi Hasil (DBH) (Andirfa, Basri, \& A.Majid, 2016) (Rizal \& Erpita, 2019). Alokasi dana perimbangan digunakan untuk pelaksanaan tugas pemerintahan serta meningkatkan kualitas pelayanan publik (Mawarni \& Abdullah, 2013) (Yunus, Sianipar, Saragih, \& Amelia, 2019) (Calen, Agustian, Damanik, \& Tannuary, 2019) (Arwin \& Hutagalung, 2019). Penelitian menunjukkan bahwa dana perimbangan berpengaruh positif dan signifikan terhadap belanja modal, artinya kenaikan dana perimbangan maka akan searah dengan kenaikan belanja modal (Calen, Agustian, Damanik, \& Tannuary, 2019) (Nurdiwaty, Zaman, \& Kristinawati, 2017). Sedangkan penelitian di kabupaten/ kota provinsi Bali menunjukkan hasil yang berbeda dimana dana perimbangan tidak berpengaruh terhadap belanja modal (Badjra, Mustanda, \& Abudanti, 2017) (Sirait \& Panjaitan, 2018) (Sirait, 2019).
Adanya perbedaan hasil penelitian pada beberapa daerah provinsi di Indonesia memotivasi penulis untuk mengkaji kembali mengenai pengaruh pendapatan asli daerah dan dana perimbangan terhadap belanja modal di kabupaten/kota provinsi Sumatera Utara. Adapun hipotesis penelitian berdasarkan kajian di atas adalah sebagai berikut:

H1 : Pendapatan Asli Daerah (PAD) berpengaruh positif terhadap belanja modal.

$\mathrm{H} 2$ : Dana perimbangan berpengaruh positif terhadap belanja modal.

\section{METODE PENELITIAN}

\subsection{Objek dan Sampel Penelitian}

Penelitan ini dilakukan di kabupaten/kota Provinsi Sumatera Utara, dimana populasi digunakan sebagai sampel penelitian yang terdiri dari 33 kabupaten/kota tahun 2010 s.d 2018 yaitu berjumlah 297 sampel. Data penelitian bersumber dari situs Direktorat Jenderal Perimbangan Keuangan Pusat dan Daerah (http://www.djpk.depkeu.go.id).

\subsection{Definisi Operasional Variabel}

Pendapatan asli daerah adalah realisasi penerimaan pendapatan asli daerah yang bersumber dari pengelolaan sumber daya daerah di kabupaten/kota Provinsi Sumatera Utara tahun 2010-2018 (Calen, Agustian, Damanik, \& Tannuary, 2019), (Sirait, 2019).

Dana perimbangan adalah realisasi dana yang diperoleh dari pemerintah pusat untuk pemerataan pembangunan daerah di kabupaten/kota Provinsi Sumatera Utara tahun 2010-2018.

Belanja modal adalah realisasi belanja daerah berupa aset tetap yang masa manfaatnya lebih dari satu tahun anggaran di Kabupaten/Kota Provinsi Sumatera Utara tahun 2010-2018.

\subsection{Teknik Analisis Data}

Penelitian ini menggunakan analisis regresi data panel dengan Eviews 10, dimana persamaan regresi linear berganda dalam penelitian ini adalah: $\mathrm{Y}_{\mathrm{it}}=\alpha+\beta 1 \mathrm{X} 1_{\mathrm{it}}+\beta 2 \mathrm{X} 2_{\mathrm{it}}+\mathrm{e}_{\mathrm{it}}$ 
Dimana:

$$
\begin{array}{ll}
\mathrm{t} & : \text { Tahun } \\
\mathrm{Y} & : \text { Belanja Modal } \\
\alpha & : \text { Konstanta } \\
\beta_{1-2} & : \text { Koefisien Regresi } \\
\mathrm{X} 1 & : \text { Pendapatan Asli Daerah } \\
\mathrm{X} 2 & : \text { Dana perimbangan } \\
\mathrm{e} & : \text { Error: }
\end{array}
$$

\section{HASIL DAN PEMBAHASAN}

\subsection{Analisis Statistik Deskriptif}

Analisis ini digunakan untuk mengetahui gambaran suatu data yang ditinjau dari nilai minimum, nilai maksimum, nilai ratarata (mean), dan nilai standar deviasi. Dalam penelitian ini, variabel yang digunakan dalam

\begin{tabular}{|c|c|c|c|}
\hline Variable & BM & PAD & DP \\
\hline Min & 16.833 .467 .955 & 1.057 .429 .832 & 61.664 .021 .038 \\
\hline Max & 997.475 .991 .90 & 1.739.756.922.63 & 2.157 .180 .424 .94 \\
\hline Mean & $\begin{array}{r}2 \\
205.863 .174 .03\end{array}$ & 4 & 6 \\
\hline $\begin{array}{c}\text { Std. } \\
\text { Deviation }\end{array}$ & $1,395 \mathrm{E}+11$ & 105.686 .223 .167 & 670.198 .387 .266 \\
\hline
\end{tabular}
perhitungan statistik deskriptif adalah nilai belanja modal (BM), pendapatan asli daerah (PAD) dan dana perimbangan (DP). Gambaran statistik deskriptif disajikan sebagai berikut.

Tabel 3.1. Statistik Deskriptif Berdasarkan Variabel BM, PAD dan DP

Sumber: Hasil Olah Software Eviews 10

Berdasarkan Tabel 3.1, diketahui nilai minimum dari $\mathrm{BM}$ adalah 16.833.467.955 , sementara nilai maksimum dari $\mathrm{BM}$ adalah 997.475.991.902. Rata-rata BM adalah 205.863.174.030, dengan standar deviasi 1,395. Diketahui nilai minimum dari PAD adalah 1.057.429.832, sementara nilai maksimum dari PAD adalah 1.739.756.922.634. Rata-rata PAD adalah 105.686.223.167, dengan standar deviasi 2,438. Diketahui nilai minimum dari DP adalah 61.664.021.038, sementara nilai maksimum dari DP adalah 2.157.180.424.946. Rata-rata DP adalah 670.198.387.266, dengan standar deviasi 3,674 .

\subsection{Menentukan Model Estimasi antara Fixed Effect Model (FEM) dan Random Effect Model (REM) dengan Uji}

\section{Hausman}

Dalam penelitian ini, untuk menentukan apakah model estimasi FEM atau REM yang membentuk model regresi, maka dilakukan uji Hausman. Berikut hasil berdasarkan uji Hausman dengan menggunakan Eviews 10.

Tabel 3.2 Hasil dari Uji Hausman

\begin{tabular}{llll}
\hline \hline Test Summary & \multicolumn{3}{c}{ Chi-Sq. Statistic Chi-Sq. d.f. Prob. } \\
\hline \hline Cross-section random7.561968 & 2 & 0.0228 \\
\hline
\end{tabular}

Berdasarkan Tabel 3.2, diketahui nilai probabilitas adalah 0,0228 . Karena nilai probabilitas $0,0228<0,05$, maka model fixed effect model (FEM) digunakan sebagai model estimasi.

\subsection{Pengujian Hipotesis}

Pada pengujian hipotesis, akan dilakukan analisis koefisien determinasi, pengujian pengaruh simultan (uji $\mathrm{F}$ ), dan pengujian pengaruh parsial (uji t). Nilai statistik dari koefisien determinasi, uji $\mathrm{F}$, dan uji t tersaji pada Tabel 3.3.

\section{Tabel 3.3 Nilai statistik dari Koefisien Determinasi,Uji F, dan Uji t}

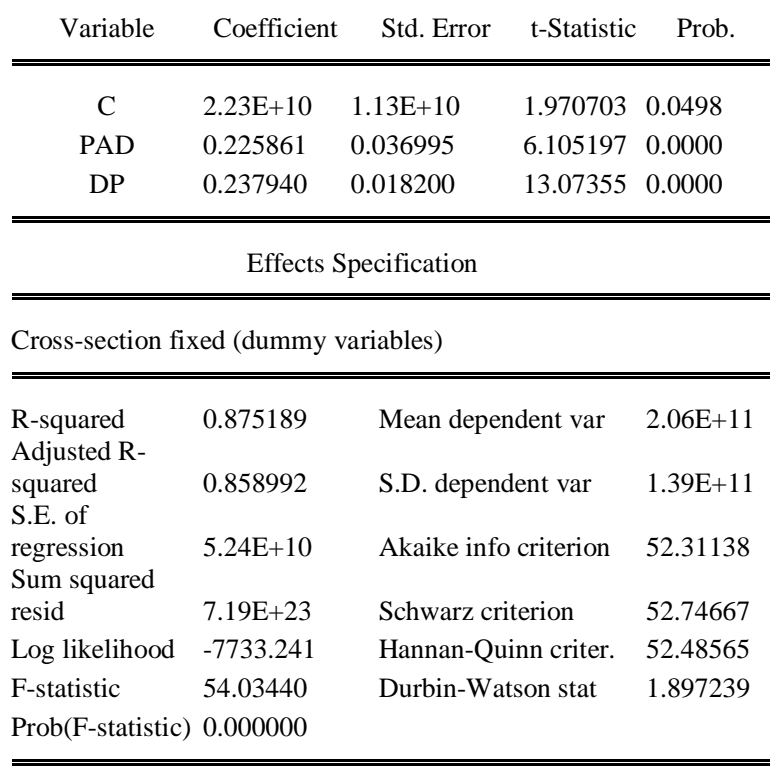

Sumber: Hasil Olah Software Eviews 10 


\subsection{Analisis Koefisien Determinasi}

Berdasarkan Tabel 3.3, nilai koefisien determinasi ( $R$-squared) sebesar $R^{2}=0,8751$. Nilai tersebut dapat diartikan bahwa pendapatan asli daerah dan dana perimbangan secara simultan mempengaruhi belanja modal sebesar $87,51 \%$, sisanya sebesar $12,49 \%$ dipengaruhi oleh faktor lainnya.

\subsection{Uji Signifikansi Pengaruh Simultan (Uji} F)

Uji $F$ bertujuan untuk menguji adanya pengaruh variabel bebas secara simultan terhadap variabel tak bebas. Berdasarkan Tabel 3.3, diketahui nilai Prob. (F-statistics), yakni $0,00000<0,05$, dapat disimpulkan bahwa variabel bebas, yakni PAD dan dana perimbangan memiliki pengaruh yang signifikan terhadap belanja modal.

\subsection{Persamaan Regresi Data Panel dan Uji Signifikansi Pengaruh Parsial (Uji t)}

Berdasarkan Tabel 3.3, diperoleh persamaan regresi linear berganda sebagai berikut.

$\mathrm{Y}=2,23+0,22 \mathrm{PAD}+0,23 \mathrm{DP}+\mathrm{e}$

Berdasarkan Tabel 3.3, diketahui:

1. PAD berpengaruh positif terhadap belanja modal, dengan nilai koefisien regresi 0,22 dan signifikan dengan nilai Prob. 0,0000 < 0,05 . Sehingga PAD berpengaruh positif signifikan terhadap belanja modal. Dalam hal ini, hipotesis pertama dalam penelitian ini diterima. Peningkatan pendapatan asli daerah akan searah dengan peningkatan belanja modal di kabupaten/kota provinsi Sumatera Utara, demikian juga sebaliknya jika terjadi penurunan pada penerimaan pendapatan asli daerah maka akan terjadi penurunan pada belanja modal. Pendapatan asli daerah harus tetap digali sebagai sumber penerimaan yang optimal misalnya yang bersumber dari pajak dan retribusi daerah sehingga belanja modal dapat direalisasikan untuk membangun atau memperbaiki infrastruktur dan fasilitas publik.

2. Dana perimbangan berpengaruh positif terhadap kemandirian keuangan daerah, dengan nilai koefisien regresi 0,23 dan signifikan dengan nilai Prob. $0,0000<0,05$. Sehingga dana perimbangan berpengaruh positif signifikan terhadap belanja modal. Dalam hal ini, hipotesis kedua dalam penelitian ini diterima. Peningkatan dana perimbangan akan searah dengan peningkatan belanja modal di kabupaten/kota provinsi Sumatera Utara, demikian juga sebaliknya jika terjadi penurunan pada penerimaan dana perimbangan maka akan terjadi penurunan pada belanja modal.

\section{KESIMPULAN}

Dari penelitian diatas, maka dapat disimpulkan bahwa pendapatan asli daerah berpengaruh positif terhadap belanja modal. Demikian juga dengan dana perimbangan berpengaruh positif terhadap belanja modal. Peningkatan pendapatan asli daerah dan dana perimbangan akan menyebabkan peningkatan pada belanja modal. Saran yang disampaikan adalah agar dalam penelitian selanjutnya dapat menambah variabel seperti pembiayaan daerah, pertumbuhan ekonomi, kinerja keuangan pemerintah daerah untuk mendukung serta menguatkan hasil penelitian ini.

\section{REFERENSI}

Adyatma, E., \& Oktaviani, R. M. (2015). PENGARUH PENDAPATAN ASLI DAERAH DAN DANA ALOKASI UMUM TERHADAP BELANJA MODAL DENGAN PERTUMBUHAN EKONOMI SEBAGAI PEMODERASI. Dinamika Akuntansi Perbankan \& Keuangan, 190 - 205.

Andirfa, M., Basri, H., \& A.Majid, M. (2016). PENGARUH BELANJA MODAL, DANA PERIMBANGAN DAN PENDAPATAN ASLI DAERAH TERHADAP KINERJA KEUANGAN KABUPATEN DAN KOTA DI PROVINSI ACEH. Jurnal Administrasi Akuntansi : Program Pascasarjana Unsyiah, 30-38.

Arwin , A., \& Hutagalung, D. S. (2019). Pengaruh Harga dan Kualitas Pelayanan terhadap Keputusan Pembelian pada PT. 
Sari Melati Kencana Pematangsiantar. Jesya (Jurnal Ekonomi \& Ekonomi Syariah), 189-198.

Asmawati, A., Saragih, A., Panjaitan, N. J., \& Kumala, C. (2019). Analisis Potensi Penerimaan Pajak Daerah Dan Retribusi Daerah Kota Pematangsiantar. Owner: Riset dan Jurnal Akuntansi, 339-349.

Badjra, I. B., Mustanda, I., \& Abudanti, N. (2017). KONTRIBUSI PENDAPATAN ASLI DAERAH DAN DANA PERIMBANGAN TERHADAP BELANJA MODAL DAN KINERJA KEUANGAN DAERAH PROVINSI BALI. Jurnal Akuntansi Indonesia, xxx.

Calen, C., Agustian, C., Damanik, A. H., \& Tannuary, A. (2019). Prosedur Pengelolaan Produk Deposito pada PT. BPRS Amanah Bangsa. Owner: Riset dan Jurnal Akuntansi, 154-161.

Juniawan, M. A., \& Suryantini, N. P. (2018). PENGARUH PAD, DAU DAN DAK TERHADAP BELANJA MODAL KOTA DAN KABUPATEN DI PROVINSI BALI. E-Jurnal Manajemen, 1255 - 1281.

Mawarni, D., \& Abdullah, S. (2013). Pengaruh Pendapatan Asli Daerah dan Dana Alokasi Umum terhadap Belanja Modal serta Dampaknya terhadap Pertumbuhan Ekonomi Daerah (Studi pada Kabupaten dan Kota di Aceh). Jurnal Akuntansi ISSN, 0164.

Novianto, R., \& Hanafiah, R. (2015). Pengaruh Pendapatan Asli Daerah, Dana Perimbangan dan Kinerja Keuangan Terhadap Alokasi Belanja Modal Pada Pemerintah Kabupaten/Kota di Provinsi Kalimantan Barat. Jurnal Ekonomi, 1-22.

nufus, h., \& Asmara, J. A. (2017). PENGARUH PENDAPATAN SENDIRI DAN DANA PERIMBANGAN TERHADAP BELANJA MODAL DENGAN DANA OTONOMI KHUSUS SEBAGAI PEMODERASI PADA KAB/KOTA DI PROVINSI ACEH. Jurnal Ilmiah Mahasiswa Ekonomi Akuntansi, 1-9.

Nurdiwaty, D., Zaman, B., \& Kristinawati, E.

\begin{tabular}{|c|c|}
\hline ANALISIS & PENGARUH \\
\hline PERTUMBUHAN & EKONOMI, \\
\hline PENDAPATAN & DAERAH, \\
\hline DANA PERIMBANGAN & DAN LAIN- \\
\hline LAIN PENDAPATAN & YANG SAH \\
\hline TERHADAP BELANJA & MODAL DI \\
\hline KABUPATEN/KOTA JA & WA TIMUR. \\
\hline
\end{tabular}

Pelealu, A. M. (2013). PENGARUH DANA ALOKASI KHUSUS (DAK), DAN PENDAPATAN ASLI DAERAH (PAD) TERHADAP BELANJA MODAL PEMERINTAH KOTA MANADO TAHUN 2003-2012. JURNAL EMBA: JURNAL RISET EKONOMI, MANAJEMEN, BISNIS DAN AKUNTANSI, 1189-1197.

Pratiwi, N. A. (2019). PENGARUH PENDAPATAN ASLI DAERAH DAN DANA ALOKASI UMUM TERHADAP BELANJA MODAL. Jurnal Ilmiah Manajemen Ekonomi dan Akuntansi, 105120.

Priambudi, W. (2017). PENGARUH PENDAPATAN ASLI DAERAH DAN DANA ALOKASI UMUM TERHADAP BELANJA MODAL PADA KABUPATEN DAN KOTA DI PULAU JAWA TAHUN 2013. Nominal, 136-147.

Rizal, Y., \& Erpita, E. (2019). Pengaruh Pendapatan Asli Daerah Terhadap Belanja Modal di Kota Langsa. Jurnal Samudra Ekonomika, 74-83.

Sirait, S. (2019). Motivasi Sebagai Faktor Peningkatan Kinerja Kepolisian. Jurnal Ekonomi dan Bisnis, 2(1), 167-177.

Sirait, S., \& Panjaitan, S. (2018). ANALISIS PENGARUH PANGSA PASAR PEMBIAYAAN DAN NON PERFORMING FINANCING (NPF) TERHADAP PROFITABILITAS PADA BANK SYARIAH. Jurnal Ekonomi dan Bisnis (EK\&BI), 76-82.

Suryana, S. (2018). Pengaruh Pendapatan Asli Daerah (PAD), Dana Alokasi Umum (DAU), Dana Alokasi Khusus (DAK) Terhadap Belanja Modal. Jurnal Ilmiah Manajemen \& Bisnis, 67-74. 
Tuasikal, A. (2008). PENGARUH DAU, DAK, PAD, DAN PDRB TERHADAP BELANJA MODAL PEMERINTAH DAERAH KABUPATEN/KOTA DI INDONESIA. Jurnal Telaah Riset Akuntansi, 142-154.

Wandira, A. G. (2013). PENGARUH PAD, DAU, DAK, DAN DBH TERHADAP PENGALOKASIAN BELANJA MODAL. Accounting Analysis Journal, 45-51.

Yawa, H., \& Runtu, T. (2015). PENGARUH DANA ALOKASI UMUM (DAU) DAN PENDAPATAN ASLI DAERAH (PAD) TERHADAP BELANJA MODAL DI KOTA MANADO. Jurnal Berkala Ilmiah Efisiensi, 390-400.

Yunus, M., Sianipar, O. L., Saragih, K. Y., \& Amelia, A. (2019). Deteksi Financial Statement Fraud Berdasarkan Perspektif Pressure dalam Fraud Triangle. Owner: Riset dan Jurnal Akuntansi, 350-360. 